\title{
Comparative suitability of aphids, thrips and mites as prey for the flower bug Orius sauteri (Hemiptera: Anthocoridae)
}

\author{
Su WANG ${ }^{1,2}$, J.P. MICHAUD ${ }^{3, *}, \mathrm{XIAO}_{\mathrm{LING}}$ TAN $^{1,2}$ and FAN ZHANG ${ }^{1}$ \\ ${ }^{1}$ Institute of Plant and Environment Protection, Beijing Academy of Agriculture and Forestry Sciences, Beijing, China \\ ${ }^{2}$ College of Plant Protection, Northwest Agriculture and Forestry University, Yangling, Shaanxi, China \\ ${ }^{3}$ Department of Entomology, Kansas State University, Agricultural Research Center-Hays, Hays, KS, USA; e-mail: jpmi@ksu.edu
}

Key words. Hemiptera, Anthocoridae, Orius sauteri, biological control, development, fecundity, fertility, reproduction

\begin{abstract}
The predatory bug Orius sauteri (Poppius) (Hemiptera: Anthocoridae) is an important biological control agent in Asia that is often released on field crops and in greenhouses to control pests on vegetable and ornamental plants. This study compared the developmental and reproductive performance of $O$. sauteri on monotypic diets of four aphid species, western flower thrips, and twospotted spider mite. Thrips emerged as the optimal prey type, consistent with findings for many other Orius spp. A diet of Frankliniella occidentalis (Pergande) yielded the fastest development, largest adult body size, shortest pre-oviposition period, and highest fecundity and longevity. Tetranychus urticae (Koch) was the next most suitable prey by most performance measures. Among aphids, Myzus persicae (Sulzer) was the most suitable and Aphis gossypii Glover the least suitable, with Aphis craccivora Koch and Megoura japonica (Matsumura) intermediate. Female $O$. sauteri were larger than males and female body mass varied more with prey type than did that of males. Despite the variation in performance among prey, all prey species yielded equally good juvenile survival and none would be expected to negatively impact the numerical response of $O$. sauteri in biological control applications where these arthropods form part of the prey complex.
\end{abstract}

\section{INTRODUCTION}

Flower bugs in the genus Orius (Hemiptera: Anthocoridae) are efficient predators of numerous arthropod pests and are widely reared for release in augmentation biological control programs in various agricultural and horticultural settings (Glenister, 1998; Paulitz, 2001; Arnó et al., 2008; Bosco et al., 2008; Chow et al., 2010; Wong \& Frank, 2012). Orius spp. consume a wide range of prey, including aphids, thrips and herbivorous mites, often supplementing their diet with vegetable material (Coll, 1998; Lattin, 1999). As for most predators, the variety and quality of food consumed influences Orius spp. development, reproduction and overall biological performance (Kiman \& Yeargan, 1985; Bush et al., 1993; Richard \& Schmidt, 1996). Consequently, diet composition is an important consideration in mass-reared cultures of these species.

Thrips (Thysanoptera) are cosmopolitan pests of many important agricultural plants (Stuart et al., 2011) and are preferred prey for many Orius spp. (Castañé et al., 2002; Salehi et al., 2011). Flower bugs have proven efficacious biological control agents against many thrips species, including Frankliniella occidentalis (Pergande) (Blaeser et al., 2004; Chow et al., 2010), Frankliniella bispinosa (Morgan) (Shirk et al., 2012), Thrips palmi Karny (Kawai, 1995; Carvalho et al., 2011; Hemerik \& Yano, 2011) and Scirtothrips dorsalis Hood (Dogramaci et al., 2011). Many aphid species also represent acceptable prey. For example, cotton aphid, Aphis gossypii Glover, soybean aphid, Aphis glycines Matsumura, and peach aphid, Myzus persicae Sulzer, have all been recorded as prey of Orius insidiosus (Say) (Bush et al., 1993; Armer et al., 1998; Rutledge \& O’Neil, 2005). Both Macrosiphum euphorbiae (Thomas) and A. gossypii are suitable prey for Orius laevigatus (Fieber) and Orius majusculus (Reuter) (Alvarado et al., 1997). Similarly, Orius similis will readily prey on Aphis fabae (Scopoli), A. gossypii, Acyrthosiphon pisum (Harris), M. persicae and Aphis pomi DeGeer, although these aphids vary considerably in suitability (Sengonca et al., 2008). Herbivorous mites are also included in the natural diet of many Orius spp. and almost any life stage of mite may be consumed, including eggs (El-Basha et al., 2012). For example, O. insidiosus has proven to be a key predator suppressing populations of red spider mite, Panonychus ulmi (Koch), in Indian apple orchards (Bhardwaj et al., 2010) and O. minutus contributes to control of Tetranychus urticae (Koch) on apple in Japan (Toyoshima \& Osakabe 2005). In laboratory feeding trials in Iran, O. minutus showed prey perference for, and better performance on, T. urticae compared to Thrips tabaci (Lindeman) (Fathi \& Nouri-Ganbalani, 2009).

In China, the native flower bug Orius sauteri (Poppius) has been recorded preying on aphids, thrips, whiteflies, mites and the eggs of moths in a range of field crops, orchards and greenhouse vegetables (Yano, 1996; Guo et al., 2002). Since its successful augmentation in agroecosystems (Wu et al., 2010), demand for O. sauteri among farmers has driven technological efforts to develop improved

\footnotetext{
* Corresponding author.
} 
rearing procedures, alternative diets, and artificial oviposition substrates (Guo \& Wan, 2001; Murai et al., 2001; Guo et al., 2002; Tan et al., 2010). With these considerations in mind, we compared the relative suitability of six herbivorous arthropods as prey for $O$. sauteri. All candidate prey are naturally consumed by this species in field and greenhouse settings, so tests were designed to determine the most suitable prey for development and reproduction of O. sauteri in mass-reared cultures, and the consequences of consuming these prey for $O$. sauteri populations in biological control contexts.

\section{MATERIAL AND METHODS}

\section{Insect colonies}

All insects were reared in climate-controlled growth chambers (Sanyo ${ }^{\circledR}, \mathrm{MH}-351$, Japan) set to $25 \pm 1{ }^{\circ} \mathrm{C}, 60-70 \% \mathrm{RH}$, and a photoperiod of 16L:8D under white LED light with an illumination intensity of 2000 lux, conditions previously shown to be suitable for O. sauteri (Nagai \& Yano, 1999). A total of $451 O$. sauteri adults (201 males and 250 females) were collected from an alfalfa field $\left(40^{\circ} 14^{\prime} \mathrm{N}, 116^{\circ} 13^{\prime} \mathrm{E}\right)$ in Changping County, Beijing, China during late August and early September, 2011. The bugs were placed in plastic boxes $(12.0 \times 8.0 \times 4.5 \mathrm{~cm})$ covered with mesh nylon net, 20 per box and provided with a mixture of all six prey species ad libitum on excised pieces of their respective food plants, refreshed daily; broad beans stems (ca. $5.0 \mathrm{~cm}$ in length) were provided as an oviposition substrate. Aphis gossypii was reared on cotton, Gossypium hirsutum L., M. persicae on tobacco, Nicotiana tobacum L., Aphis craccivora Koch and Megoura japonica (Matsumura) on broad bean, Vicia faba L., F. occidentalis on cucumber, Cucumus sativus L. and T. urticae on soybean, Glycine max (L.). The various prey species were reared on their respective food plants in aluminum frame cages $(70.0 \times$ $65.0 \times 45.0 \mathrm{~cm}$ ) covered with nylon mesh net. The $O$. sauteri colony was reared for $2-3$ generations prior to use in experiments. All experiments were conducted in climate-controlled growth chambers (as above) under the same physical conditions as the stock colonies.

\section{Development and immature survival}

Bean stems bearing eggs of $O$. sauteri were collected and placed into plastic Petri dishes $(9.0 \mathrm{~cm}$ diameter) and covered with mesh nylon to permit ventilation. Clear plastic Petri dishes ( $4.5 \mathrm{~cm}$ diameter) were prepared for experimental replicates by placing a moist filter paper $(2.5 \mathrm{~cm}$ diameter $)$ in the bottom of each dish to maintain $60-70 \% \mathrm{RH}$. Dishes were randomly assigned to one of six monotypic diet treatments (M. persicae, A. craccivora, M. japonica, A. gossypii, T. urticae, or F. occidenta$l i s)$ and each was provisioned with prey (all life stages) ad libitum on leaves of their respective plant. Newly hatched nymphs were then transferred to these dishes, 10 per dish, using a fine, camel hair brush. Each dish was then covered with a film of perforated Parafilm ${ }^{\circledR}$. All dishes were changed and prey refreshed daily until all bugs molted to adults. We recorded the total duration of nymphal development and weighed newly molted adults individually on an electronic balance (Mettler-Toledo ${ }^{\circledR}$, AL104, Greifensee, Switzerland, with precision $0.01 \mathrm{mg}$ ) to obtain their fresh mass. Nymphal survival rate (\%) in each replicate was calculated as the no. adults emerged / no. first instar nymphs hatched. Five replications were conducted with each prey species.

\section{Reproduction}

Fourth instar nymphs were isolated from the stock colony and sexed once they molted to the adult stage. Individual pairs $(\mathrm{n}=$

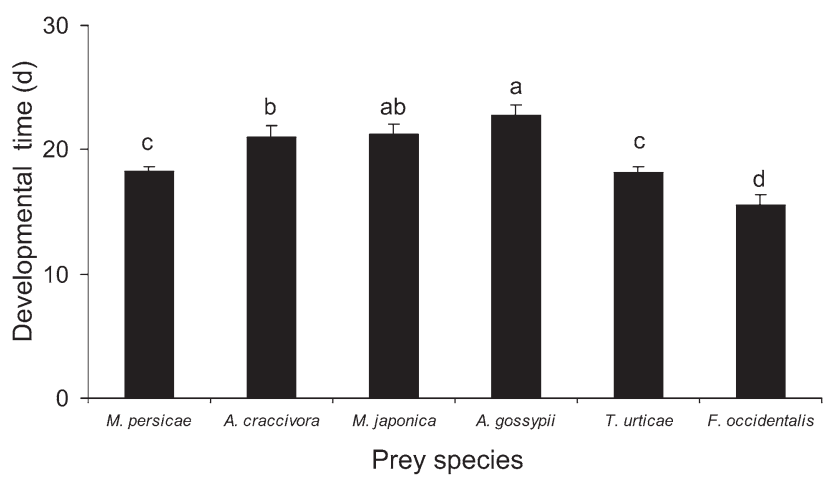

Fig. 1. Mean duration (+SE) of O. sauteri nymphal development when fed different arthropod prey. Columns bearing the same letters were not significantly different (Bonferroni, $\alpha=$ $0.05)$.

10 per treatment, replicated five times) were established in $100 \mathrm{ml}$ glass jars covered with nylon mesh (as above). Jars were each assigned to one of six monotypic prey treatments and supplied with ad libitum diets of each prey species and 10 fresh broad bean stems for oviposition, both renewed daily. Pairs were allowed $24 \mathrm{~h}$ to mate and then males were removed and held separately. Broad bean stems bearing eggs were removed daily from each replicate, held in separate jars (as above), and examined every six hours for nymphal eclosion. The preoviposition period was measured as the time from adult molt to first oviposition. The period of oviposition, lifetime fecundity (no. eggs), egg fertility (\% eggs hatching) and longevity of males and females were all recorded. The intrinsic rate of natural increase, $\mathrm{r}_{\mathrm{m}}$, was estimated for each prey type as:

$$
\mathrm{r}_{\mathrm{m}}=\ln \mathrm{R}_{0} / \mathrm{T}
$$

where $\mathrm{R}_{0}$ is the mean number of female progeny per female and $\mathrm{T}$, the generation time.

\section{Data analysis}

Development and reproductive data were analyzed by one-way ANOVA (SPSS, 2007) and means were separated by the Bonferroni test $(\alpha=0.05)$; percentages (e.g., egg fertility) were arcsine transformed prior to analysis. A two-way ANOVA was used to analyze data for adult body mass and longevity because males and females differed in these traits. Survival and emergence rates were analyzed using the $\chi^{2}$ test.

\section{RESULTS}

\section{Development and immature survival}

Prey type affected the mean duration of $O$. sauteri nymphal development $(F=17.20$; df $=5,24 ; P<0.001$; Fig. 1$)$. Development was slowest on $A$. gossypii, followed by $M$. japonica and $A$. craccivora, and fastest on $F$. occidentalis, followed by $T$. urtica and $M$. persicae, the latter yielding similar values. The two-way ANOVA was significant overall for body mass $(F=10.63$; df $=11,48 ; P<0.001)$, with significant main effects of $\operatorname{sex}(F=51.40 ; \mathrm{df}=1,48 ; P<$ $0.001)$ and prey type $(F=11.21 ; \mathrm{df}=5,48 ; P<0.001)$ and without a significant sex*prey type interaction $(F=1.90$; df $=5,48 ; P=0.112$ ). Females were heavier than males and female body mass appeared to vary more in response to prey type, but the largest adults of both sexes were obtained on $F$. occidentalis and the smallest on $A$. craccivora (Fig. 2). The survival rate from first instar nymph to adult 


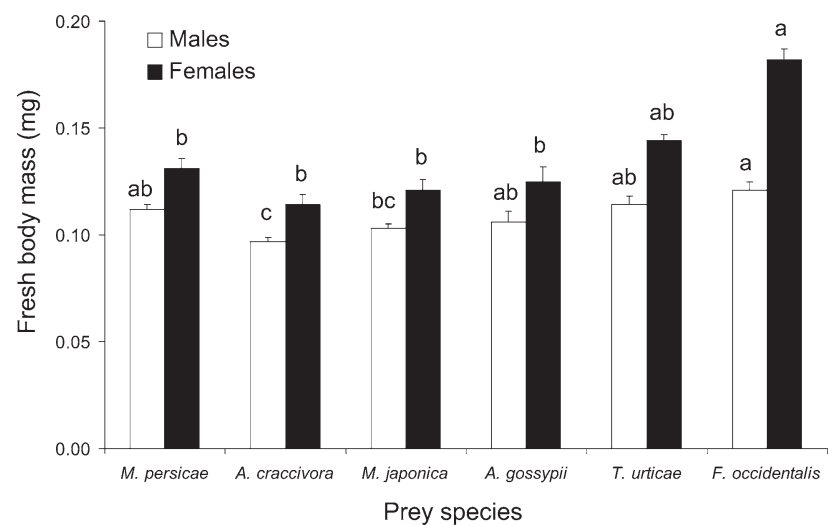

Fig. 2. Mean fresh mass at emergence of adult male and female O. sauteri $(\mathrm{n}=50$ individuals of each sex) reared on different prey species. Columns bearing the same letters were not significantly different within sexes (Bonferroni, $\alpha=0.05$ ); females were heavier than males in all cases $(P<0.05)$.

was not significantly affected by feeding treatment $\left(\chi^{2}=\right.$ 0.67 ; d.f. $=5 ; P=0.995:$ M. persicae $=78 \%$, A craccivora $=70 \%$, M. japonica $=68 \%$, A. gossypii $=64 \%$, T. urticae $=$ $74 \%$ and $F$. occidentalis $=78 \%$ ).

\section{Reproduction and longevity}

The preoviposition period of mated $O$. sauteri females adult varied with prey type $(F=21.51$; df $=5,24 ; P<$ $0.001)$; it was shortest on F. occidentalis and T. urticae and longer on the aphid species (Fig. 3). The two-way ANOVA of longevity was significant overall $(F=45.02$; $\mathrm{df}=11,48$; $P<0.001)$ with significant effects of both sex $(F=411.32$; df $=1,48 ; P<0.001)$ and prey type $(F=59.73$; df $=5,48$; $P<0.01)$ and without a significant sex*prey type interaction $(F=0.35$; df $=5,48 ; P=0.883)$. Males lived longer than females and the longevity of both were greatest on thrips (Fig. 4). Fecundity $(F=5.39$; df $=5,24 ; P=0.002$; Fig. 5) but not fertility $(F=1.84$; df $=5,24 ; P=0.144)$ varied significantly among prey types. Estimates of $\mathrm{r}_{\mathrm{m}}$ were as follows: $M$. persicae $=0.120$, A craccivora $=0.092, M$. japonica $=0.103$, A. gossypii $=0.090$, T. urticae $=0.124$ and $F$. occidentalis $=0.153$.

\section{DISCUSSION}

The present study reveals that the flower bug $O$. sauteri is an oligophagous predator capable of successful development and reproduction not only on thrips and mites,

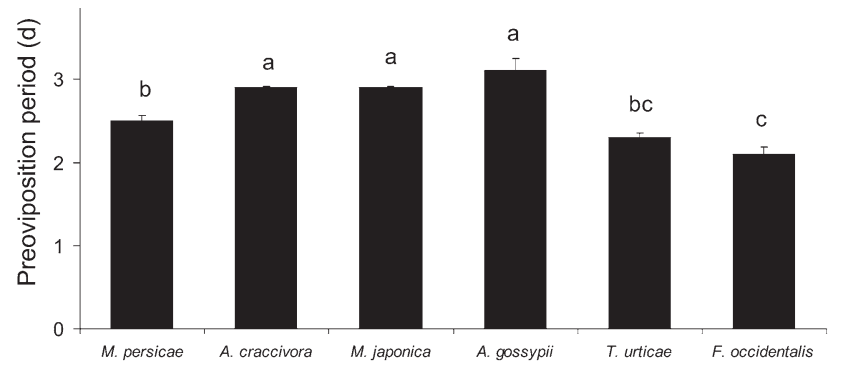

Prey species

Fig. 3. Mean $(+\mathrm{SE})$ preoviposition period of $O$. sauteri females $(n=50)$ fed on different prey species. Columns bearing the same letters were not significantly different (Bonferroni, $\alpha=0.05$ ).

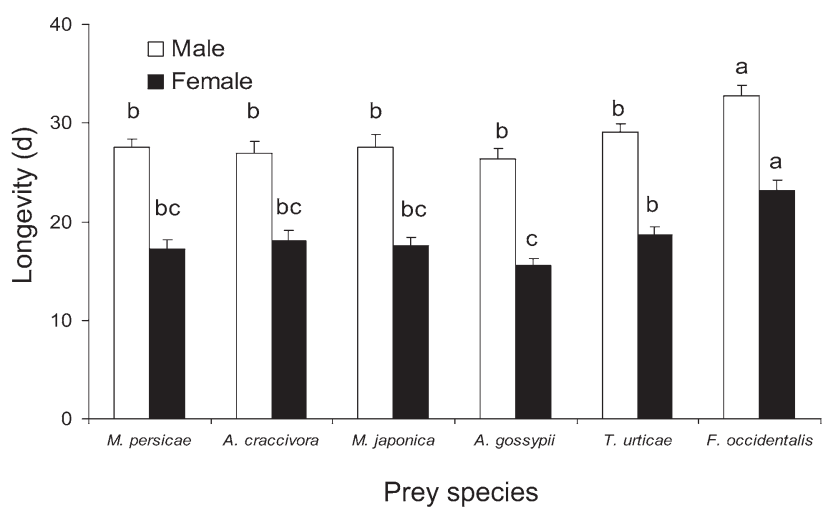

Fig. 4. Mean (+SE) longevities of adult female and male $O$. sauteri ( $\mathrm{n}=50$ individuals of each sex) fed on different prey species. Columns bearing the same letters were not significantly different within sexes (Bonferroni, $\alpha=0.05$ ); males lived longer than females in all cases $(P<0.05)$.

but also on a range of aphid species. Because pests vary in their seasonal activity within crops, the effectiveness of predators in biological control applications often hinges on their ability to utilize a range of different prey species for growth, development and reproduction. Prey specificity has often been emphasized as a desirable quality in candidate biocontrol agents, both because of the benefits of targeted impact on the pest and reduced risk of impact on non-target species (Hoy, 1999; Dixon, 2000). However, the broad diet of generalist predators may enable them to maintain a more stable presence in agroecosystems by switching among prey types as these vary in abundance over time (Murdock et al., 1985; Chang \& Kareiva, 1999). Thus, an understanding of relative prey suitability is valuable when considering the role of any predator in biological control, whether for augmentative release or conservation. It is also information necessary for the optimization of mass-rearing protocols (Thompson \& Hagen, 1999).

In the present study, F. occidentalis emerged as the most suitable prey of those tested for all aspects of $O$. sauteri development and reproduction. Previously, Zhang et al. (2007) reported natural predation by $O$. sauteri on $F$. occidentalis in China, and Kohno \& Kashio (1998) evaluated its consumption and successful development on this prey in the laboratory. Orius species have long been known to be

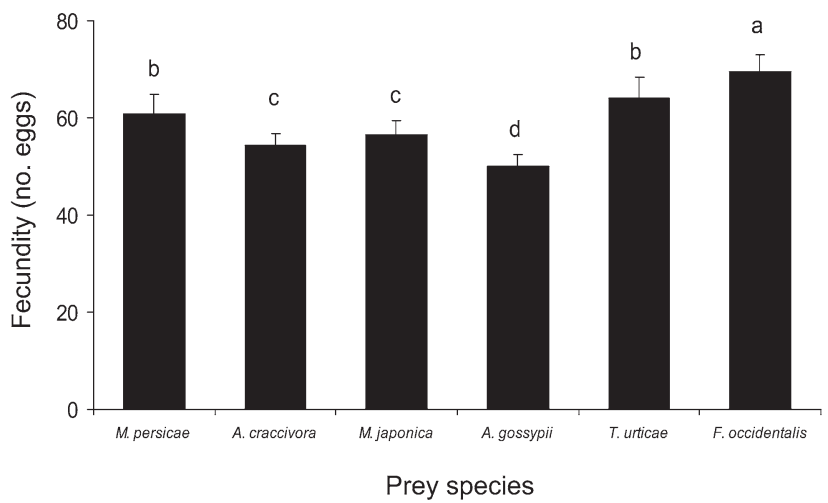

Fig. 5. Mean fecundity $(+\mathrm{SE})$ of $O$. sauteri females $(\mathrm{n}=50)$ fed on different prey species. Columns bearing the same letters were not significantly different (Bonferroni, $\alpha=0.05$ ). 
efficient predators of thrips in various agricultural settings (Kawai, 1995; Castañé et al., 2002; Funderburk, 2008). Outbreaks of $F$. occidentalis on roses, Rosa hybrida L., can be suppressed by releases of $O$. insidiosus and the bugs are compatible with predatory mites important for controlling spider mites (Chow et al., 2008, 2010). Not only can $O$. laevigatus effectively control F. occidentalis on tomato, but the bugs' oviposition in plant tissues induces wound responses that increase plant resistance to the pest (De Puysseleyr et al., 2011). In a greenhouse study on peppers, Weintraub et al. (2011) demonstrated that releases of the predatory mite Amblyseius swirskii Athias-Henriot simultaneously with $O$. laevigatus could provide similar levels of thrips control with lower release rates of bugs than when releasing only bugs, which are more expensive to produce. Even though flower bugs may exhibit preference for particular prey in the laboratory, their habitat use may correspond more to the overal productivity of a prey patch, than the relative suitability of the prey therein. For example, Venzon et al. (2002) observed that released O. laevigatus accumulated more on plants with high densities of spider mites than on plants with moderate densities of thrips, even though the latter are the preferred, and more suitable, prey species. Thus, flower bugs appear to be compatible with other predators in plantscapes where biological control of both mites and thrips is required.

Although $O$. sauteri performed best on a thrips diet, the two-spotted spider mite was a highly suitable prey for its development and reproduction, suggesting that this species has the potential to contribute significantly to spider mite control. Field studies have indicated that Orius species contribute efficacious control of native spider mites in Chinese fruit orchards (Bao \& Gu, 1999). Furthermore, although the various aphid species offered here were clearly suboptimal prey for $O$. sautieri, they were not unsuitable and still supported successful development and reproduction, suggesting that they could represent important alternative prey for bugs when mites and thrips are scarce. Whether they might contribute significantly to suppression of these aphid species will hinge on their willingness to consume aphids in the presence of preferable alternatives, something that was not explored in the present study. For example, $O$. sauteri is recognized as a significant predator of aphids in potato fields in Japan (Nakata, 1995) and $O$. insidiosus has emerged as a key source of mortality for soybean aphid, Aphis glycines Matsumura, in North American soybean fields despite its preference for thrips (Ragsdale et al., 2001; Rutledge \& O’Neil, 2005).

In northern China, thrips infesting greenhouse vegetables often coexist with the spider mites T. urticae and Tetranychus cinnabarinus (Boisduval) and aphids such as $M$. persicae, even though these pests vary widely in their spatial and temporal distribution in open fields. The ability of $O$. sauteri to successfully exploit all these species suggests it may be an ideal candidate for augmentation in greenhouse vegetable production, with the understanding that control of mites and aphids may occur only after thrips have been suppressed. Much effort to date has focused on applications of $O$. sauteri in greenhouse vegetables (Kajita, 1982; Kurogi et al., 1997; Nagai \& Yano, 2000; Huo et al., 2011; Jiang et al., 2011), but it may be a good prospect for augmentation in orchard ecosystems as well, since $M$. persicae and T. urticae represent two of the primary pests in orchard ecosystems in China. In summary, all six prey species tested supported successful $O$. sauteri development and reproduction, indicating that even the less suitable species could be significantly impacted by the flower bug, or serve as important alternative prey for maintaining predator populations within a crop when thrips are scarce.

ACKNOWLEDGMENTS. We thank Y. Zhang (Institute of Zoology, Chinese Academy of Sciences, Beijing, China) for reviewing an early version of manuscript. This study was supported by the National Key Basic Research Program of China (973 program), No. 2013CB127601.

\section{REFERENCES}

Alvarado P., Batalà O. \& Alomar O. 1997: Efficiency of four Heteroptera as predators of Aphis gossypii and Macrosiphum euphorbiae (Homoptera: Aphididae). — BioControl 42: 215226.

Armer C., Wiedenmann R. \& Bush D. 1998: Plant feeding site selection on soybean by the facultatively phytophagous predator Orius insidiosus. — Entomol. Exp. Appl. 86: 109-118.

Arnó J., Roig J. \& Riudavets J. 2008: Evaluation of Orius majusculus and O. laevigatus as predators of Bemisa tabaci and estimation of their prey preference. - Biol. Contr. 44: 1-6.

Bao J.Z. \& Gu D.X. 1999: Chinese Biological Control. Shanxi Science and Technology Press, Taiyuan, 664 pp.

Bhardwaj S., Sharma S. \& Bhardwaj S.P. 2010: Response of Orius insidiosus (Say) (Hemiptera: Anthocoridae) on European Red mite Panonychus ulmi (Tetranychidae) on apple. - Indian J. Entomol. 72: 297-300.

Blaeret P., Sengonca C. \& Zegula T. 2004: The potential use of different predatory bug species in the biological control of Frankliniella occidentalis (Pergande) (Thysanoptera: Thripidae). - J. Pest Sci. 77: 211-219.

Bosco L., Giacometto E. \& Tavella L. 2008: Colonization and predation of thrips (Thysanoptera: Thripidae) by Orius spp. (Heteroptera: Anthocoridae) in sweet pepper greenhouses in Northwest Italy. - Biol. Contr. 24: 1-6.

Bush L., Kring T. \& Ruberson J. 1993: Suitability of greenbugs, cotton aphids, and Heliothis virescens eggs for development and reproduction of Orius insidiosus. - Entomol. Exp. Appl. 67: 217-222.

Carvalho L.M., Bueno V.H.P. \& Castañé C. 2011: Olfactory response towards its prey Frankliniella occidentalis of wild and laboratory-reared Orius insidiosus and Orius laevigatus. - J. Appl. Entomol. 135: 177-183.

Castañé C., Riudavets J. \& Yano E. 2002: Biological control of thrips. In Albajes R., Lodovica M., van Lenteren J.C. \& Elad Y. (eds): Integrated Pest and Disease Management in Greenhouse Crops. Kluwer Academic, Dordrecht, pp. 244-253.

Chang G.C. \& Kareiva P. 1999: The case for indigenous generalists in biological control. In Hawkins B.A. \& Cornell H.V. (eds): Theoretical Approaches to Biological Control. Cambridge University Press, Camdridge, pp. 103-115.

Chow A., Chau A. \& Heinz K. 2008: Compatibility of Orius insidiosus (Hemiptera: Anthocoridae) with Amblyseius (Iphiseius) degenerans (Acari: Phytoseiidae) for control of Frankliniella occidentalis (Thysanoptera: Thripidae) on greenhouse roses. - Biol. Contr. 44: 259-270. 
Chow A., Chau A. \& Heinz K. 2010: Compatibility of Amblyseius (Typhlodromips) swirskii (Athias-Henriot) (Acari: Phytoseiidae) and Orius insidiosus (Hemiptera: Anthocoridae) for biological control of Frankliniella occidentalis (Thysanoptera: Thripidae) on roses. — Biol. Contr. 53: 188-196.

Coll M. 1998: Living and feeding on plants in predatory Heteroptera. In Coll M. \& Ruberson J. (eds): Predatory Heteroptera: Their Ecology and Use in Biological Control. Thomas Say Publications, Lanham, MD, pp. 89-129.

De Puysseleyr V., Hofte M. \& De Clerce P. 2011: Ovipositing Orius laevigatus increase tomato resistance against Frankliniella occidentalis feeding by inducing the wound response. Arth. Plant Inter. 5: 71-80.

Dixon A.F.G. 2000: Insect Predator-Prey Dynamics, Ladybird Beetles and Biological Control. Cambridge University Press, Cambridge, $257 \mathrm{pp}$.

Dogramaci M., Arthurs S.P., Chen J.J., McKenzie C., Irrizary F. \& OsBorne L. 2011: Management of chilli thrips Scirtothrips dorsalis (Thysanoptera: Thripidae) on peppers by Amblyseius swirskii (Acari: Phytoseiidae) and Orius insidiosus (Hemiptera: Anthocoridae). - Biol. Contr. 59: 340-347.

El-Basha N.A., Salman M.S. \& Osman M.A. 2012: Functional response of Orius albidipennis (Hemiptera: Anthocoridae) to the two-spotted spider mite Tetranychus urticae (Acari: Tetranychidae). - J. Entomol. 9: 248-256.

Fathi S.A.A. \& Nouri-Ganbalani G. 2009: Prey preference of Orius niger (Wolff) and O. minutus (L.) from Thrips tabaci (Lindeman) and Tetranychus urticae (Koch). - J. Entomol. 6: $42-48$.

FUnDERBURK J. 2008: Management of western flower thrips (Thysanoptera: Thripidae) in fruiting vegetables. - Fla Entomol. 92: $1-6$.

GLenISTER C. 1998: Predatory heteropterans in augmentative biological control: An industry perspective. In Coll M. \& Ruberson J. (eds): Predatory Heteroptera: Their Ecology and Use in Biological Control. Thomas Say Publications, Lanham, MD, pp. 199-208.

GuO J. \& Wan F. 2001: Use of Kalanchoe blossfeldiana as an oviposition plant for mass-rearing Orius sauteri (Hemiptera: Anthocoridae). - Chin. J. Biol. Contr. 17: 53-56.

Guo J., Wan F. \& Wu M. 2002: Comparison of successive rearing of Orius sauteri with aphids and Trichogramma pupae reared in artificial host eggs. - Chin. J. Biol. Contr. 18: 58-61.

Hemerik L. \& Yano E. 2011: Scaling up from individual behaviour of Orius sauteri foraging on Thrips palmi to its daily functional response. - Popul. Ecol. 53: 563-569.

Hoy M.A. 1999: Parasitoids and predators in management of arthropod pests. In Metcalf R.L. \& Luckmann W.H. (eds): Introduction to Pest Management. John Wiley and Sons, New York, pp. 129-198.

Huo J., Xu X. \& WANG E. 2011: Orientation of Orius sauter (Hemiptera: Anthocoridae) to healthy or injured bean plants by western flower thrips and / or twospotted spider mites. - Chin. J. Appl. Entomol. 48: 569-572.

Jiang Y.L., Wu Y.Q., Duan Y. \& GaO X.G. 2011: Control efficiencies of releasing Orius sauteri (Heteroptera: Anthocoridae) on some pests in greenhouse pepper. - Chin. J. Biol. Contr. 27: 414-417.

KaJtTA H. 1982: Predation by adult Orius sauteri Poppius (Hemiptera: Anthocoridae) on the greenhouse whitefly, Trialeurodes vaporariorum (Westwood) (Homoptera: Aleyrodidae). - Appl. Entomol. Zool. 17: 424-425.

KawaI A. 1995: Control of Thrips palmi Karny (Thysanoptera: Thripidae) by Orius spp. (Heteroptera: Anthocoridae) on greenhouse eggplant. - Appl. Entomol. Zool. 30: 1-7.
Kiman Z. \& Yeargan K. 1985: Development and reproduction of the predator Orius insidiosus (Hemiptera: Anthocoridae) reared on diets of selected plant material and arthropod prey. - Ann. Entomol. Soc. Am. 78: 464-467.

Kohno K. \& Kashio T. 1998: Development and prey consumption of Orius sauteri (Poppius) and O. minutus (L.) (Heteroptera: Anthocoridae) on greenhouse eggplant. - Appl. Entomol. Zool. 30: 1-7.

Kurogi S., NaKamura M. \& Kawasaki Y. 1997: Studies on integrated control of major insect pests of the sweet pepper in a greenhouse 3: Control of Thrips palmi with two species of predators, Orius sauteri and Amblyseius cucumeris. - Proc. Assoc. Plant Prot. Kyushu 43: 106-109.

Latrin J. 1999: Bionomics of the Anthocoridae. - Annu. Rev. Entomol. 44: 207-231.

Murai T., Narai Y. \& Sugiura N. 2001: Utilization of germinated broad bean seeds as an oviposition substrate in mass rearing of the predatory bug, Orius sauteri (Poppius) (Heteroptera: Anthocoridae). - Appl. Entomol. Zool. 36: 489-495.

Murdoch W.M., Chesson J. \& Chesson P.I. 1985: Biological control in theory and practice. - Am. Nat. 125: 344-366.

NAGAI K. \& Yano E. 1999: Effects of temperature on the development and reproduction of Orius sauteri (Poppius) (Heteroptera: Anthocoridae), a predator of Thrips palmi Karny (Thysanoptera: Thripidae). — Appl. Entomol. Zool. 34: 223-229.

Nagai K. \& Yano E. 2000: Predation by Orius sauteri (Poppius) (Heteroptera: Anthocoridae) on Thrips palmi Karny (Thysanoptera: Thripidae): Functional response and selective predation. - Appl. Entomol. Zool. 35: 565-574.

NAKATA T. 1995: Population fluctuations of aphids and their natural enemies on potato in Hokkaido, Japan. - Appl. Entomol. Zool. 30: 129-138.

Paulitz T. 2001: Biological control in greenhouse systems. Annu. Rev. Entomol. 39: 103-133.

Ragsdale D., Landis D., Brodeur J., Heimpel G. \& Desneux N. 2001: Ecology and management of the soybean aphid in North America. - Annu. Rev. Entomol. 56: 375-399.

Richard P. \& Schmidt J. 1996: The effects of selected dietary supplements on survival and reproduction of Orius insidiosus (Say) (Hemiptera: Anthocoridae). - Can. Entomol. 128: 171-176.

Rutledge C. \& O’NeIL R. 2005: Orius insidiosus (Say) as a predator of the soybean aphid, Aphis glycines Matsumura. - Biol. Contr. 31: 56-64.

Salehi F., Baniameri V., Sahragard A. \& Hajizadeh J. 2011: Investigation on prey preference and switching behavior of the predatory bug, Orius niger Wolff under laboratory conditions (Heteroptera: Anthocoridae). - Munis Entomol. Zool. 6: 425-432.

Sengonca C. Ahmadi K. \& Blaeser P. 2008: Biological characteristics of Orius similis Zheng (Heteroptera, Anthocoridae) by feeding on different aphid species as prey. - J. Plant Dis. Plant Prot. 1: $32-38$.

Shirk P.D., Shapiro J.P., Reitz S.R., Thomas J.M.G., Koenig R.L., HaY-Roe M.M. \& Buss L.J. 2012: Predator-prey relationships on Apiaceae at an organic farm. - Environ. Entomol. 41: 487-496.

SPSS 2007: SPSS 16.0 User's Guide. SPSS Inc. Chicago, IL.

Stuart R., Gao Y. \& Lei Z. 2011: Thrips: pests of concern to China and the United States. - Agric. Sci. China 10: 867-892.

Tan X., Wang S., Li X. \& Zhang F. 2010: Optimization and application of microencapsulated artificial diet for Orius sauteri (Hempitera: Anthocoridae). — Acta Entomol. Sin. 53: 891900 . 
Thompson S. \& Hagen K. 1999: Nutrition of entomophagous insects and other arthropods. In Bellows T. \& Fisher T. (eds) Handbook of Biological Control. Academic Press, New York, pp. 594-652.

Toyoshima S. \& Osakabe M. 2005: Effects of artificially released Neoseiulus californicus (Acari: Phytoseiidae) and naturally occurring Orius minutus (Hemiptera: Anthocoridae) on Tetranychus urticae (Acari: Tetranychidae) population in apple orchard without insecticides. - Ann. Rep. Soc. Plant Prot. N. Jap. 56: 188-190.

Venzon M., Janssen A. \& Sabelis M.W. 2002: Prey preference and reproductive success of the generalist predator Orius laevigatus. — Oikos 97: 116-124.

Weintraub P., Pivonia S. \& Steinberg S. 2011: How many Orius laevigatus are needed for effective western flower thrips, Frankliniella occidentalis, management in sweet pepper? Crop Prot. 30: 1443-1448.
Wong S. \& Frank S. 2012: Influence of banker plants and spiders on biological control by Orius insidiosus (Heteroptera: Anthocoridae). - Biol. Contr. 63: 181-187.

Wu Y., Zhao M., Yang S., Duan Y. \& Jiang Y. 2010: Predations of Orius sauteri (Hemiptera: Anthocoridae) on four insect pests. - Chin. J. Biol. Contr. 26: 13-17.

YANo E. 1996: Biology of Orius sauteri (Poppius) and its potential as a biocontrol agent for Thrips palmi. - IOBC/WPRS Bull. 19: 203-206.

Zhang A., Yu Y. \& Zhang S. 2007: Predation of Orius sauteri adult on adults of western flower thrips (Frankliniella occidentalis), an invasive insect pest. — Acta Ecol. Sin. 27: 1903-1909.

Received November 27, 2013; revised and accepted February 7, 2014 Prepublished online March 27, 2014 